\title{
PARTICIPACIÓN ESPAÑOLA EN LOS CONGRESOS DE LA SOCIEDAD INTERNACIONAL DE UROLOGÍA EN EL SIGLO XX
}

\author{
Mariano Pérez Albacete, Jesús Tornero Ruíz, Gerardo Server Pastor e Ignacio Ponce de León \\ Castell?.
}

Servicio de Urología. Hospital Universitario Virgen de la Arrixaca. Murcia. y Urólogo Seniorr. Barcelona. España.

\begin{abstract}
Resumen.- OBJETIVO: Con ocasión del centenario de la constitución en 1907 de la denominada primero Asociación y, más tarde, Sociedad Internacional de Urología, señalamos los temas tratados y analizamos la presencia de urólogos españoles en el acto fundacional así como el papel desempeñado y sus aportaciones en los congresos de la Sociedad celebrados en el siglo XX.

MÉTODOS: Entresacamos datos de la información recogida en diferentes publicaciones periódicas, de las memorias de algunos de los participantes y de las actas de los congresos.
\end{abstract}

RESULTADOS: Hemos obtenido notas de la reunión constitutiva de la Asociación Internacional y de sus dos congresos y luego de los veinticinco de la Sociedad. Extraemos, principalmente de las actas editadas por el secretario de la reunión, la asistencia de los urólogos españoles y su contribución con ponencias o comunicaciones así como la relevancia que han tenido al desempeñar cargos en el seno de la organización.

CONCLUSIONES: Desde 1907 la presencia de urólogos españoles tanto en la Asociación como en la Sociedad Internacional de Urología ha sido constante. En la primera mitad del siglo, años en los que nuestra Urología se encontraba en un periodo de consolidación, fueron los responsables de los principales servicios urológicos de los grandes hospitales del país los que podían transmitir su experiencia con un nivel y calidad equiparables a los del resto de los europeos. En la segunda, una vez recuperadas las naciones de los episodios bélicos, prosigue la actividad científica con una creciente aportación española conforme se extiende por todo el país la creación de los Hospitales de la Seguridad Social con servicios jerarquizados de Urología en los que se realiza el estudio y el análisis de sus casuísticas y se inician la investigación clínica y experimental, lo que permite que las comunicaciones españolas se incrementen de modo notable sobre todo en los congresos celebrados en poblaciones de habla castellana o en los europeos. Como consecuencia de su participación, en España se han desarrollado tres de los veinticinco congresos organizados en el siglo XX. La presencia española en los órganos rectores de la Sociedad se vio favorecida con la presidencia del profesor D. Salvador Gil Vernet por dos periodos consecutivos.

Palabras clave: Sociedad Internacional de Urología. Congresos de Urología. Historia de la Urología. 
Summary.- OBJECTIVES: With the occasion of the Centenary of the Constitution in 1907 of the International Society of Urology, initially named Association, we point at the topics treated and analyze the presence of the Spanish urologists in the foundation act as well as their role and contributions in the meetings during the 2Oth century.

METHODS: We obtained the data from the information in various periodic publications, from the memories of some participant urologists and from the meeting records.

RESULTS: We obtained notes from the foundation meeting of the International Association and two congresses, and also from the 25 congresses of the Society. We mainly extract data from the records edited by the meeting secretary, about the assistance of Spanish urologists and their contribution with conferences or communications and also about the relevance they have had holding positions within the organization.

CONCLUSIONS: From 1907 the presence of Spanish urologists both in the Association and the International Society of Urology has been a constant. During the first half of the century, a time when our Urology was in a period of consolidation, the people in charge of the main urology departments in big hospitals in our country where the ones that could transmit their experience, with a level and quality comparable with the rest of Europeans. During the second half, once the nations recovered from wars, the scientific activity continued with an increasing Spanish contribution, which extended all over the country with the creation of the net of Social Security hospitals. They had hierarchical urology departments that performed study and analysis of their case series and started clinical and experimental research, significantly increasing the number of Spanish communications, mainly in congresses celebrated in Spanish speaking or European cities. As a consequence of their participation, three of the 25 meetings organized during the 20th century have been held in Spain. The Spanish presence in the directing boards of the society was favoured by the presence of Dr. Salvador Gil Vernet to consecutive periods.

Keywords: International society of urology. Urology meetings. History of Urology.

\section{INTRODUCCIÓN}

En el mes de octubre de 1907, por invitación de los Drs. Félix Guyon (1831-1920) y Joaquín Albarrán (1860-1912), tuvo lugar en el Hospital Necker de París una reunión preparatoria para constituir una
Asociación Internacional de Urología, a la que acudieron una veintena de urólogos de Europa, Estados Unidos y Sudamérica; los fines propuestos eran crear un medio para mantener comunicación e información científicas, promover el intercambio entre las diversas asociaciones urológicas y fomentar la relación entre los especialistas de todo el mundo; aceptados con general beneplácito, se redactaron sus estatutos con 14 artículos, se estableció el domicilio social en París y los idiomas oficiales fueron el francés, inglés, alemán e italiano. Fue elegido presidente de la Asociación Internacional a Félix Guyon, que prolongó su mandato hasta 1914, el comité internacional quedó formado por el alemán James Israel (1848-1926) y los franceses Ernest Desnos (1853-1925) y Octave Pasteau.

Los asistentes fueron miembros fundadores, entre ellos los españoles Luís González-Bravo y Serrano (1855-1929), Carlos Negrete de los Reyes (18551932), Ángel Pulido Martín (1878-1970) y Leonardo de la Peña Díaz (1875-1957).

En 1908 se organizó el primer Congreso de la Asociación Internacional en la ciudad de París, del 30 de septiembre al 3 de octubre (Figura 1), bajo la presidencia de Joaquín Albarrán y del secretario general Ernest Desnos. Las sesiones se desarrollaron en el anfiteatro de la Facultad de Medicina y los temas de discusión fueron «Patogenia y tratamiento de las anurias», «Retenciones vesicales sin obstáculo mecánico», "Fisiología normal y patológica de la próstata» e «ndicaciones operatorias en la tuberculosis renal»; presentaron comunicaciones los españoles Bartrina Thomás, Catedrático de Patología Quirúrgica de la Universidad de Barcelona, «A propósito de las retenciones vesicales» $y$ "Contribución al estudio de la fisiología normal de la próstata» y Serrallach Mauri, «Influencia de la secreción interna del testículo sobre la vejiga», "Sobre la extirpación de la próstata» y «La inyección de prostatina, extracto de tejido prostático, citotoxina prostática y sus efectos sobre las funcionas sexuales». Hubo exposición de instrumental con variados tipos de cistoscopios, de diversas casas comerciales. Se nombraron socios a José María Bartrina Thomás (1887-1950) y a Narciso Serrallach Mauri (1875-1951), de Barcelona y a León Cardenal Pujals (1878-1960), Pedro Oroquieta, Leonardo de la Peña Díaz (1875-1957) y Alberto Suárez de Mendoza (n. 1849), de Madrid, a Fermín Aranda Fernández-Caballero (1866-1946), de Jerez de la Frontera, a Ramón Camiña Beraza, de Bilbao y a Peña, de Cádiz. Fue designado como delegado de la sección española Enrique Lluria Despau (18621925), de Madrid, y como vocales Joaquín Mestre Morer (n. 1849), de Barcelona, y Manuel Sánchez Sarachaga, de Santander. 


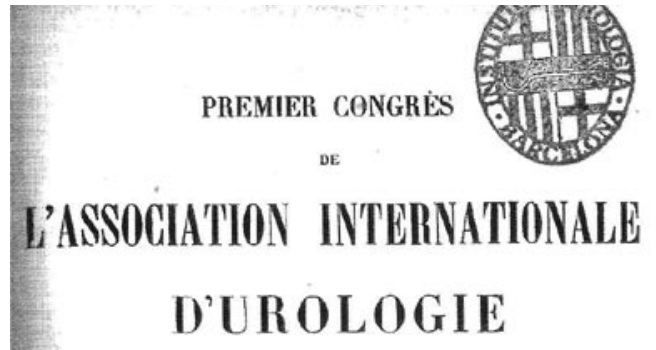

PARIS, 30 Septembre - 3 Octobre 1908

PROCÉS-VERBAUX, RAPPORTS

ET DISCUSSIONS

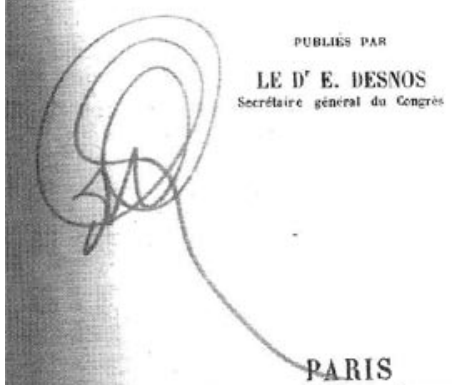

MASSON ET G", ÉDITEURS

LIRHAIRES DE L'ACADÉMIE DE MÉDECINE

420, DOELEYAM SAITT-GERLALS, 120

$\overline{1908}$

FIGURA 1. Libro de actas del I Congreso de la Asociación Internacional, París, 1908.

El segundo se desarrolla en Londres del 24 al 28 de julio de 1911, (Figura 2) sin que tengamos constancia ni de la asistencia ni de la participación de urólogos hispanos. El norteamericano Hug Young presentó su punch o sacabocados, que le permitía con control visual seccionar el tejido prostático por medio de una cuchilla, aunque sin posibilidad de hemostasia.

Del tercero, convocado en Berlín en 1914, no hemos logrado obtener datos sobre su realización ya que la declaración el día cinco de agosto de la primera guerra mundial disolvió la Asociación.

En 1919 vuelve a anunciar el francés Félix Legueu, nuevamente en París, una reunión para la reorganización de la Asociación lo que se logró pero con el cambio de nombre por el de Sociedad Internacional de Urología, S.I.U., y con la exclusión de Alemania y Austria. Constituye dicha Sociedad un comité central con sede en París y los nacionales de cuantos países forman parte, que ascendían a unos trescientos socios; ya desde sus comienzos tuvo un alto prestigio científico que se mantiene con el paso
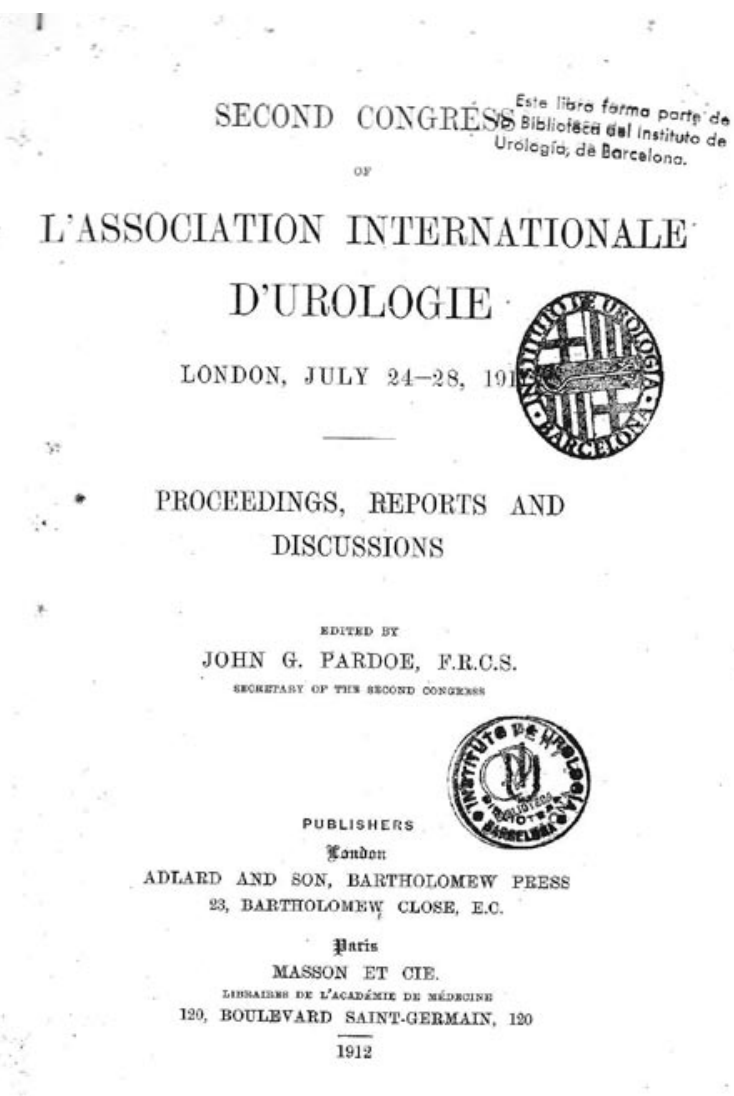

L'ASSOCIATION INTERNATIONALE

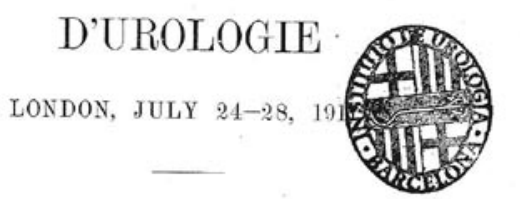

PROCEEDINGS, REPORTS AND DISCUSSIONS

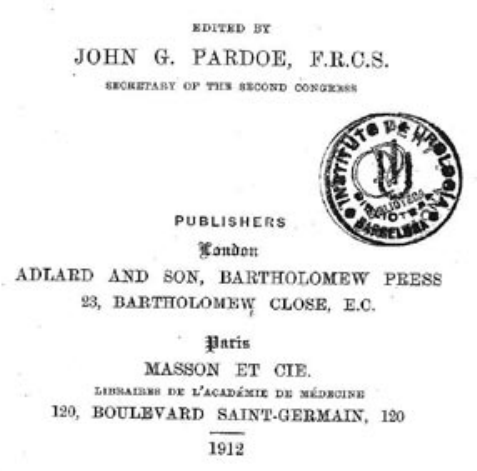

FIGURA 2. Libro de actas del II Congreso, de Londres, 1917.

de los años, su importancia residía en la selección de sus miembros, designados por un comité nacional entre los mejores especialistas del país, con un número limitado de socios, hasta 1997, en que se abolió el sistema y se redactaron unos nuevos estatutos; los congresos se organizan cada tres años, periodo en que se renueva la junta directiva, tienen una finalidad exclusivamente científica y se presentan tres ponencias sobre distintos temas, cada una asignada por separado a tres especialistas destacados en la materia, cuyas conclusiones se discuten en la sesión. Fue elegido presidente de la Sociedad el Dr. Legueu.

I Congreso, París, 1921, entre los días cinco a siete del mes de julio (Figura 3), bajo la presidencia del británico $\mathrm{H}$. Fenwick, y como secretario el profesor Desnos, se discutieron los temas «Nefritis y síndrome urémico», «De la pielografía» y «Resultados lejanos del tratamiento de los traumatismos de la uretra», en el que participaron Pedro Cifuentes Díaz (1880-1960), jefe del servicio de Urología del Hospital de la Princesa, e Isidro Sánchez Covisa (1879-1944), del Hospital Provincial, ambos de Madrid, con su experiencia y casuística. Fue nombrado 
delegado del comité español José María Bartrina y vocales, Pulido Martín y González Bravo.

II congreso, Roma, 1924, del 24 al 26 de abril. Pedro Cifuentes Díaz fue el primer español en ser invitado a desarrollar una ponencia "Resultados lejanos de las operaciones de litiasis renal», la exposición la hizo en castellano, idioma que se incluyó como oficial a partir de ese momento en la SIU. Fueron nombrados miembros Germán Asúa (18801939), Manuel Barragán y Bonet (1861-1932), Isidro Sánchez Covisa, Fernando Miraved Blanco (1880-1939), Rafael Mollá Rodrigo (1862-1930), Salvador Pascual Ríos (1887-1938), de Madrid, y Vicente Company Arnau (1881-1976), Gabriel Estapé y Pagés (1873-1924), Ricardo Lalande, Joaquín Mestre Morer (1870-1924), José Parés y Parés, Manuel Serés Ibars (1888-1927), Emilio Sacanella Vidal (1860-1931), Felipe Mestre Sancho, José María Reverter Girona (1888-1969) y Luís Frontera, de Barcelona, Enrique Alcina Quesada (1878-1943), de Cádiz y Benigno Oreja Elósegui (1880-1962), de San Sebastián.

III congreso, Bruselas, 1927, del 3 al 6 de agosto de 1927, (Figura 4) fue presidido por el responsable de la Sociedad Internacional H. Fenwick y por el belga Jean Verhooghen. Se celebró en el palacio de la Academias de Bruselas y se discutieron las ponencias "Del valor comparativo de los diversos exámenes de sangre y orina en cirugía urinaria», "Tratamiento de los tumores de la vejiga con agentes físicos» y «Tratamiento de la tuberculosis genital»; participaron con comunicaciones Isidro Sánchez Covisa, «Sobre el tratamiento de los tumores vesicales por las corrientes de alta frecuencia» y «Sobre el tratamiento de la tuberculosis genital en el hombre», y Vicente Company Arnau, jefe del servicio de Urología del Hospital de la Santa Cruz y de San Pablo, de Barcelona, "Tratamiento de los tumores de la vejiga por agentes físicos». Hubo sesiones operatorias principalmente de prostatectomías, nefrectomías y pielolitectomías.

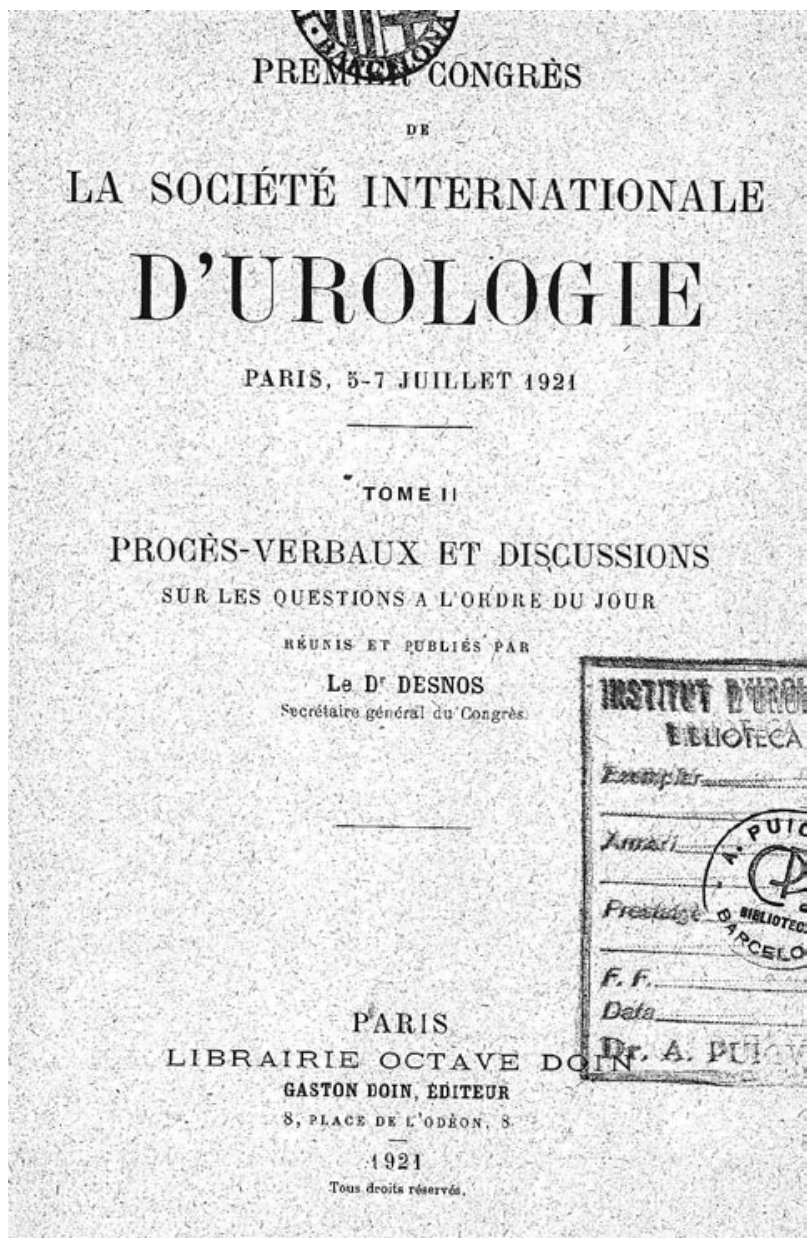

FIGURA 3. Libro de actas del I Congreso de la Sociedad Internacional, París, 1921

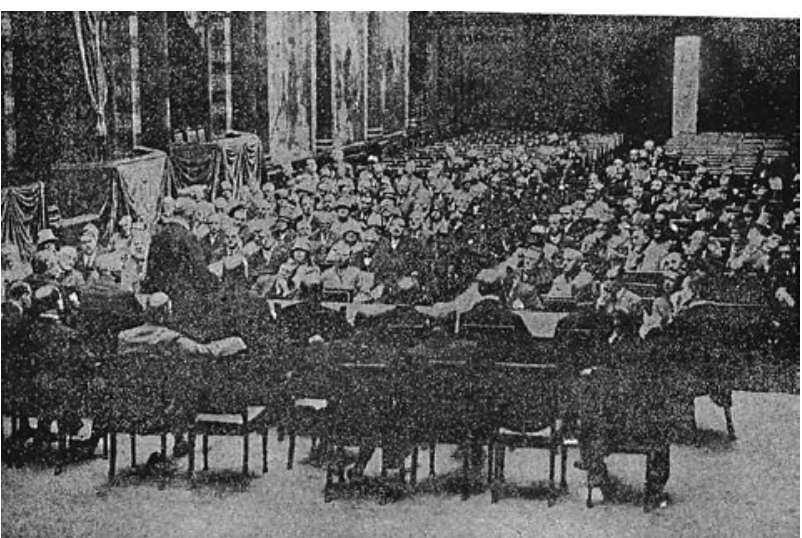

FIGURA 4. Sesión inaugural del III Congreso, en el Palacio de las Academias de Bruselas, 1927.

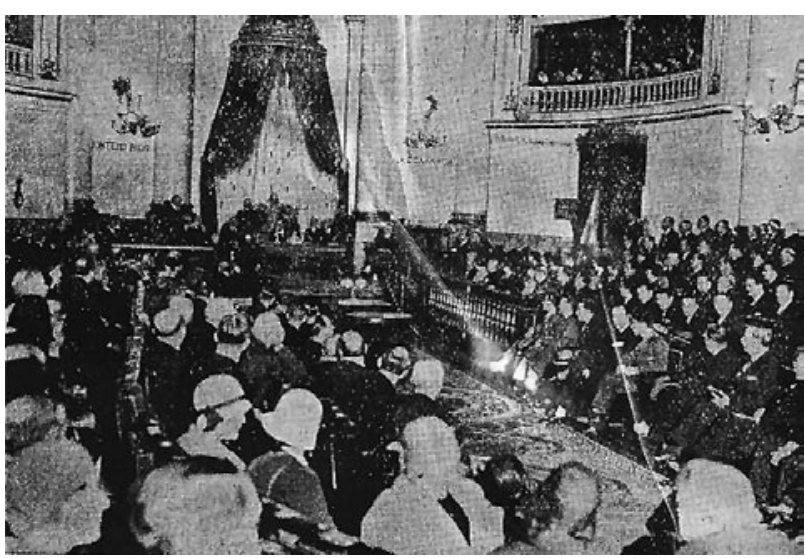

FIGURA 5. Solemne sesión inaugural del IV Congreso, presidida por el Rey Alfonso XIII. Madrid, 1930. 
En la asamblea, defendido por el Dr. Enrique Alcina Quesada, catedrático de Patología Quirúrgica de la Universidad de Cádiz y con el apoyo del resto de los españoles asistentes, José Parés, Joaquín Mestre, Fernando Miraved, Pedro Cifuentes, Julio Picatoste y Salvador Pascual, se designó Madrid como sede de la próxima reunión y, por aclamación, presidente a Luís González Bravo. En una reunión preparatoria en Madrid se eligió como delegado del comité español Isidro Sánchez Covisa y vocales Pedro Cifuentes y Narciso Serrallach y como nuevos socios al madrileño Tomás Martín Luque y Salvador Gil Vernet (1892-1987).

IV congreso, Madrid 1930, los días 7 al 12 de abril. La sesión inaugural fue presidida por el Rey Alfonso XIII (Figura 5), el norteamericano E. L. Keyes, de la Cornwell University de Nueva York, presidente de la Sociedad Internacional, y Leonardo de la Peña Díaz, catedrático de Operaciones en la Universidad Central, del congreso, que sustituyó, por el fallecimiento, en mayo anterior, del designado González Bravo, fue secretario de la reunión Salvador Pascual Ríos, jefe del servicio de Urología del Hospital Central de la Cruz Roja. La reuniones tuvieron lugar en el salón de sesiones del Senado, intervinieron como

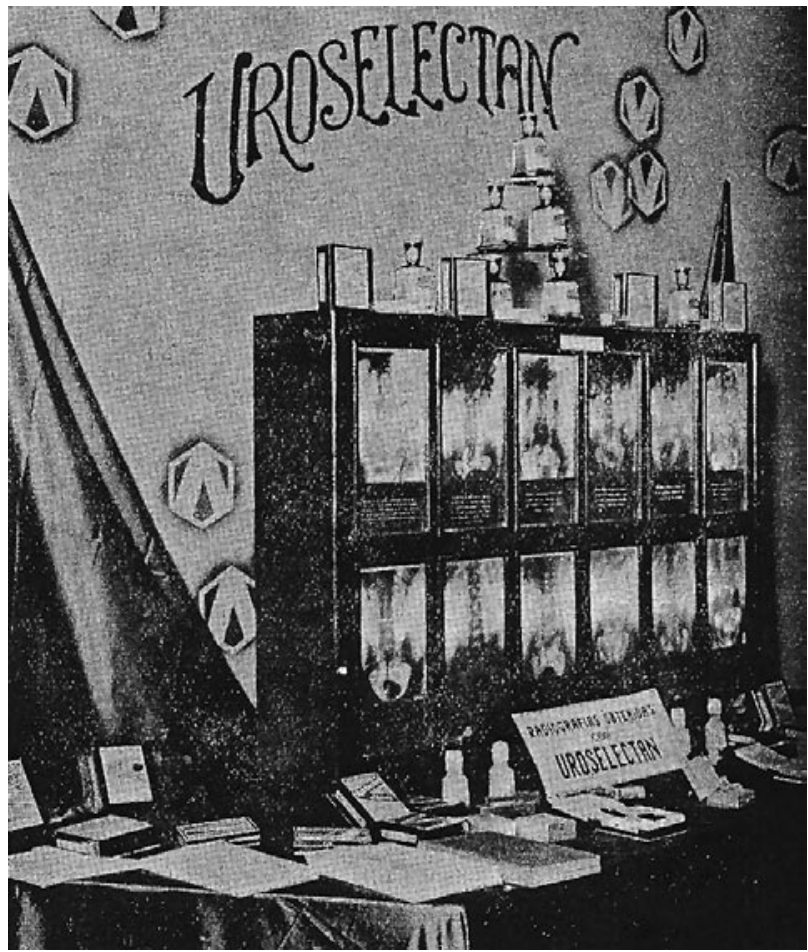

FIGURA 6. Stand del "Uroselectán" en el IV Congreso, Madrid, 1930. ponentes los madrileños Isidro Sánchez Covisa, con el tema «Etiología y tratamiento de la hidronefrosis», Ángel Pulido Martín, jefe del servicio de Vías Urinarias del madrileño Hospital de San Juan de Dios, con «Antisépticos urinarios» y el catalán Eduardo Perarnau, urólogo del Hospital San Pablo de Barcelona, con «Infecciones colibacilares del aparato urinario»; presentó una comunicación Benigno Oreja Elósegui, «Las pielonefritis en los prostatectomizados». Participaron en las discusiones los Drs. Parés, Serrallach, Cifuentes, Covisa, Company, Oreja y Pascual. Hubo operaciones todos los días en los diferentes hospitales madrileños. En este congreso el Dr. Reynaldo Dos Santos explicó su técnica de «Aortografía» y quedó consagrada la urografía de eliminación del Dr. Lichtenberg y Voelcker, con el uso intravenoso del contraste "uroselectán", (Figura 6) como prueba fundamental para el estudio de los riñones y de las vías urinarias. Asistieron las principales personalidades de la urología mundial. Como anécdota, los Reyes dieron una recepción oficial en el Palacio Real en honor de los congresistas.

V congreso, Londres, 1933, del 11 al 15 de julio de 1933 (Figura 7), presidido por el Dr. Walter, Salvador Pascual Ríos leyó su ponencia sobre «Tu-

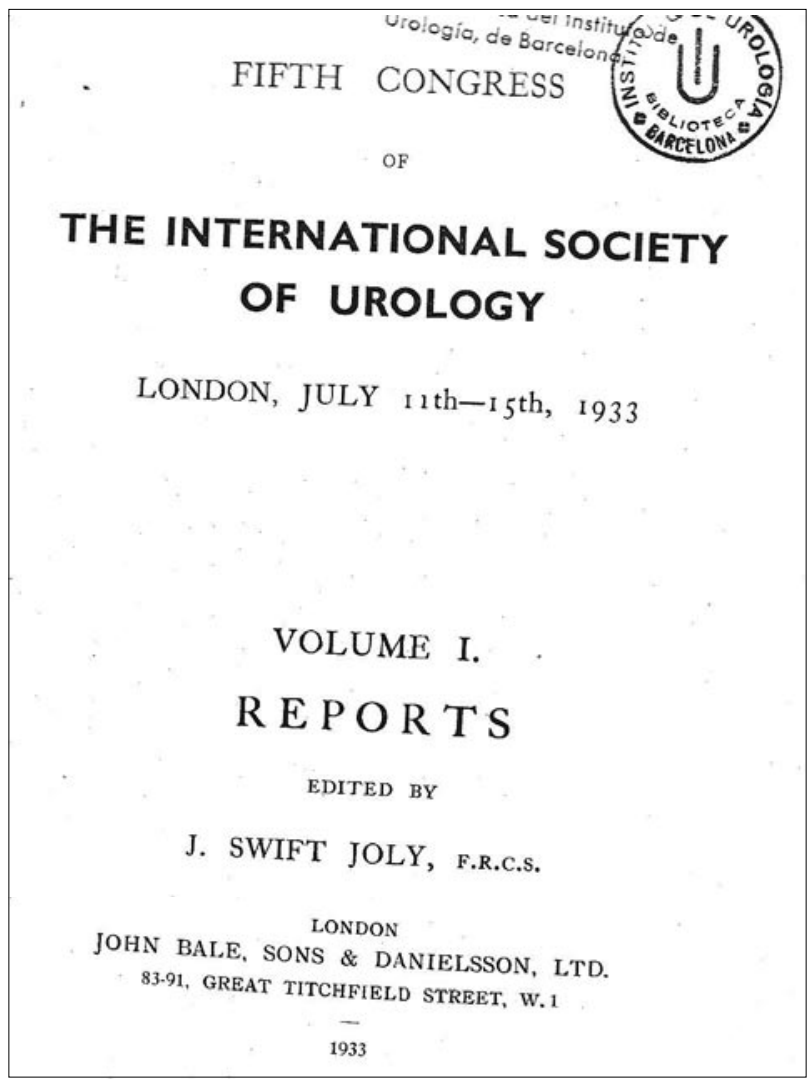

FIGURA 7. Libro de actas del V Congreso, Londres, 1933. 
mores de la pelvis renal y uréter» (Figura 8) y Pedro Cifuentes una comunicación sobre la «Urografía excretora». La asistencia de españoles fue concurrida con la presencia de veintisiete de los miembros de la Sociedad, es de señalar que Von Lichtenberg acudió para exponer su aportación de la pielografía y señalar sus ventajas.

VI congreso, Viena, 1936. La sexta convocatoria transcurrió en el verano de 1936 pero, dados los acontecimientos en nuestro país, no pudieron acudir los urólogos españoles.

VII congreso, Saint Moritz, 1947. La segunda guerra mundial interrumpió forzosamente la celebración de las reuniones y fue en la neutral Suiza donde se reanudaron las sesiones de la SIU, del 25 al 28 de agosto de 1947 (Figura 9); por las dificultades del viaje en aquellos momentos únicamente se desplazaron los españoles José María Bartrina Thomás y el madrileño Tomás de la Maza Saavedra (18961975), urólogo del servicio del Hospital Provincial de Madrid, que disertó sobre "Causa o tratamiento preventivo de los cálculos urinarios»; ambos expusieron, además, su experiencia en el tema "Conducta del urólogo ante la tuberculosis urinaria». Ángel Pulido Martín participó con la comunicación sobre «Técnica de trasplantación de los uréteres». Era el delegado español accidental del comité internacional Pedro Ci-

\section{FIRST SESSION}

11th July, 1933

\section{FIRST QUESTION}

Tumours of the Renal Pelvis and Ureter

REPORTERS.

Professor Salvador Pascual (Madrid).

Professor F. VAN DEN BRANden (Brussels).

Mr. J. SwiFt Joly (London).

Report by Professor S. Pascual (see Volume 1, page 82).

Report by Professor F. Van den Branden (sce Volume I, page 139).

Report by Mr. J. Swift Joly (see Volume I, page 211).

FIGURA 8. Ponencia del Dr. Salvador Pascual, "Tumores de la pelvis renal y del uréter». fuentes y fue elegido en su puesto Ángel Pulido Martín quien logró que se incrementase en tres miembros más el número de delegados españoles, vacantes que fueron cubiertas por los madrileños Luís Cifuentes Delatte (1907-2005), Agustín Hidalgo y FernándezCaro (1903-1968), Joaquín Páez Ríos (1899-1973), Alfonso de la Peña Pineda (1904-1971), Enrique Pérez Castro (1908-1980), el catalán Antonio Puigvert Gorro (1905-1987) y el canario José Ponce Arias (1893-1979).

En la propuesta de sede para el siguiente congreso se barajó la opción de Norteamérica o la de Portugal y fue la ciudad de Lisboa la elegida, pero en el mes de marzo de 1949 comunicaron los urólogos lisboetas las grandes dificultades que tenían y que les imposibilitaban el organizarlo, por lo que el delegado español Dr. Pulido propuso celebrarlo en la ciudad de Barcelona al secretario general de la SIU, el parisino Dr. Fey; reunidos en el mes de marzo se aceptó la oferta y se designó presidente de honor al profesor José María Bartrina Thomás, del congreso a Salvador Gil Vernet, secretario general y organizador a Antonio Puigvert Gorro y vicepresidentes a Vicente Company Arnau y Narciso Serrallach Mauri; como vocales fueron nombrados Antonio Moya Prats, Antonio Cols Baqué y Luís Batalla Sabaté.

VIII congreso, Barcelona, 1949. Fue el segundo organizado en España, se desarrolló en la Ciudad Condal del 20 al 23 de septiembre, (Figura 10) en la Real Academia de Medicina, y el acto inaugural fue abierto por el presidente de la Asociación, el norteamericano George Gilbert Smith, junto con el del comité local, Salvador Gil Vernet, con la asistencia de delegados de 26 países. Las sesiones de trabajo

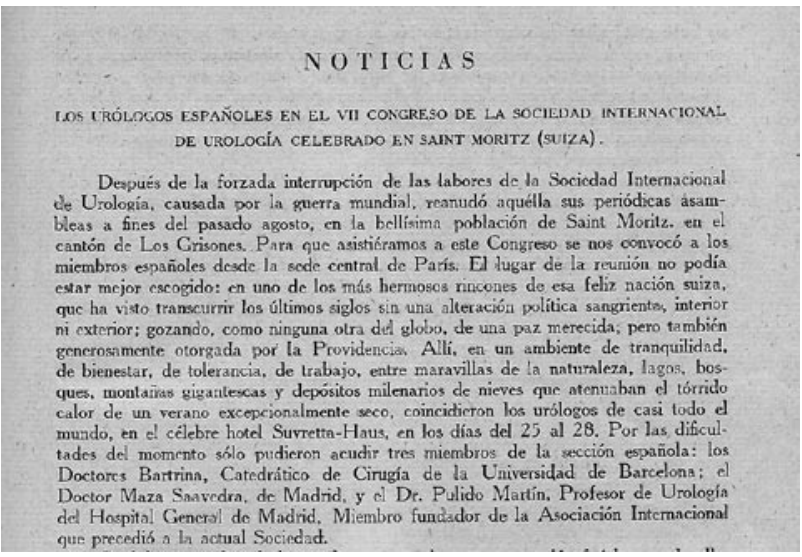

FIGURA 9. Noticias del VII Congreso, Saint Moritz, Arch. Esp. de Urol. IV (2): 179, 1947. 


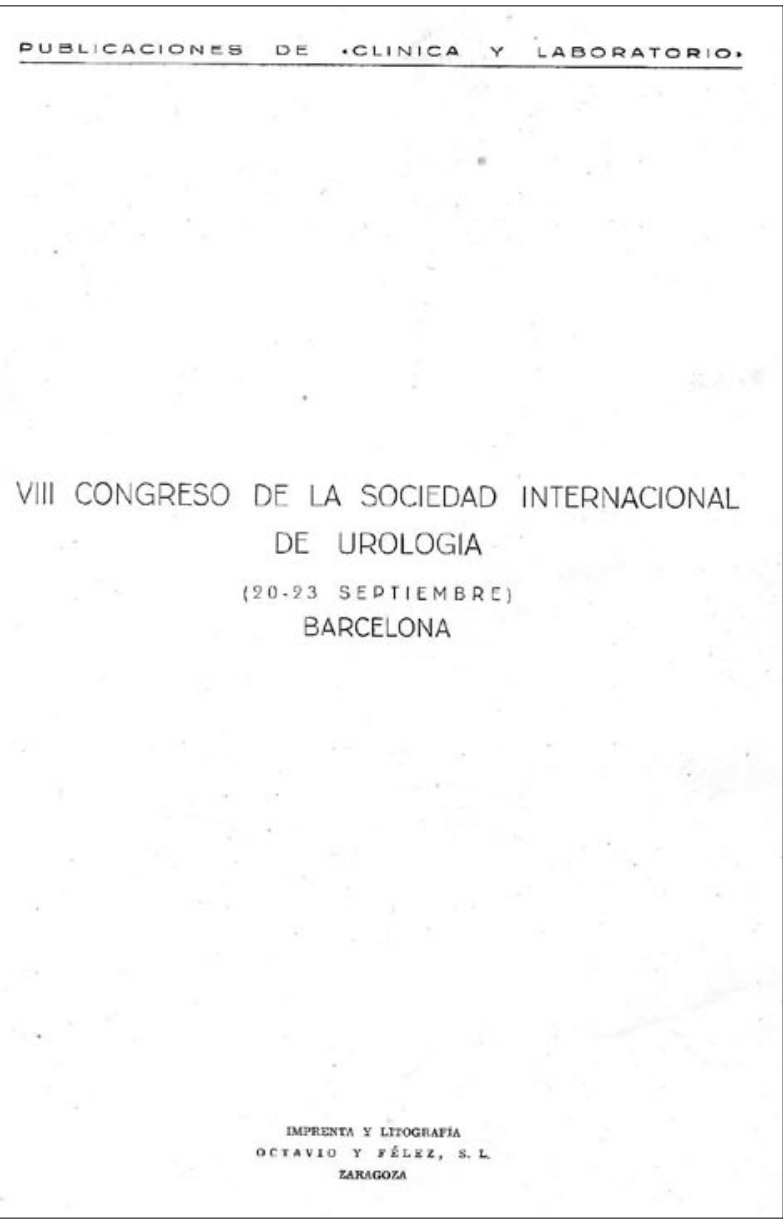

FIGURA 10. VIII Congreso, Barcelona, 1949.

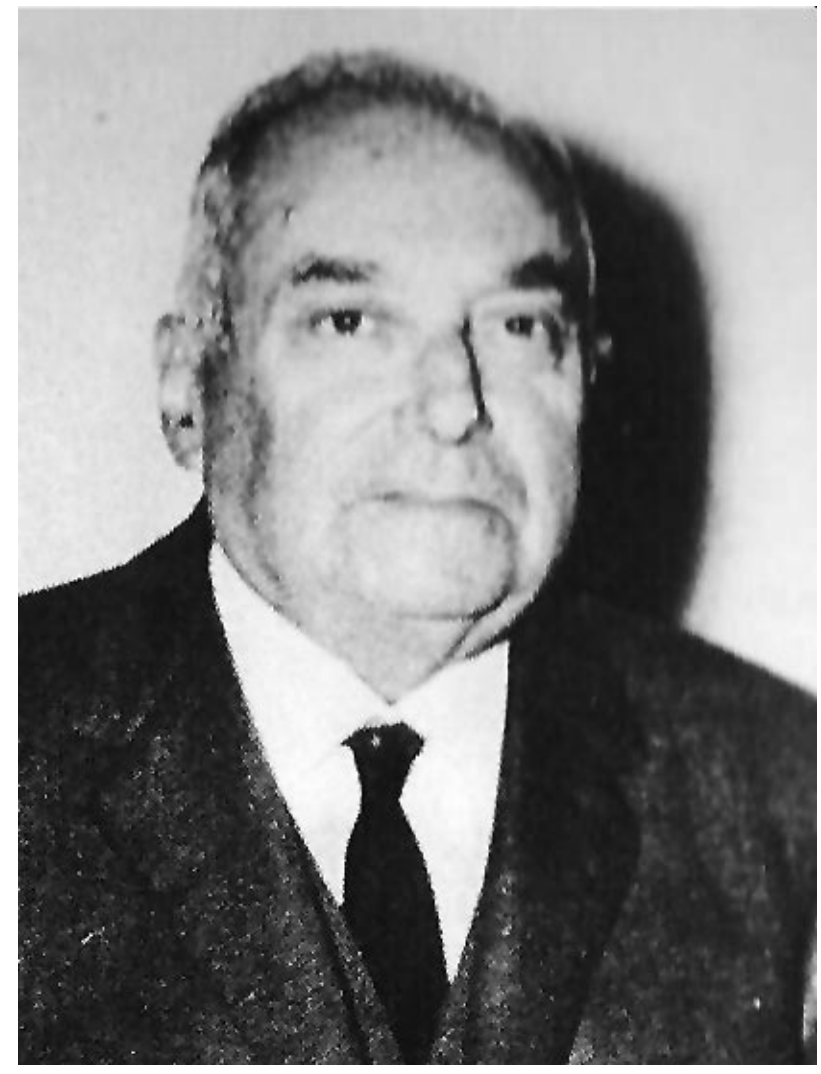

FIGURA 1 1. Salvador Gil Vernet (1892-1987) Catedrático de Anatomía de la Facultad de Medicina de la Universidad de Barcelona, presidente del VIII Congreso, Barcelona, 1949 discurrieron en el anfiteatro de la Facultad de Medicina, Gil Vernet expuso la ponencia «Tratamiento de las obstrucciones del cuello vesical» (Figura 11), en la que expuso sus estudios sobre la patología prostática, participaron en las discusiones los españoles Cifuentes Díaz, Company Arnau, de la Maza Saavedra, de la Peña Pineda, Hidalgo Fernández Caro, Ponce de León Alberni (1893-1973), Serrallach Mauri y Puigvert Gorro, este último presentó la película «Adenomectomía por vía perineal». Hubo intervenciones quirúrgicas en los servicios urológicos de los hospitales barceloneses. En el Hospital Clínico, Salvador Gil Vernet realizó una prostatosigmoidostomía pararectal y una prostatectomía total y Gil-Vernet Vila una ureterosigmoidostomía, en el de la Cruz Roja, Gausa Raspall una prostatectomía retropúbica y una amputación de pene, en el Instituto de Urología del Dr. Puigvert, efectuó éste una adenomectomía por vía perineal y una ureteropieloplastia, Antonio Cols una adenomectomía perineal y una epididimectomía y Antonio Moya Prats una nefrectomía, en el de la San- ta Cruz y San Pablo, Company Arnau, jefe de servicio de Vías Urinarias, una cistotomía y José María Lucena, adjunto al mismo, una nefrectomía secundaria, Pablo Bretón Plandiuria jefe del servicio del Hospital del Sagrado Corazón una resección transuretral y otra Martín Sensat, con lo que se destacó la técnica quirúrgica personal de los urólogos españoles.

En la asamblea general se incrementó en catorce el número de miembros españoles y fueron nombrados Rafael Alcalá Santaella (1896-1959) y Nicasio Benlloch Giner (1888-1957), de Valencia, Mariano Bretón Plandiuria (1892-1955), Pedro Gausa Raspall (1904-1992), Antonio Moya Prats, Ignacio Orsola Martín (n. 1906), Francisco Serrallach Juliá (1899-1986) y Luís Batalla Sabaté, de Barcelona; Fernando Sánchez Covisa (1896-1986) y Emilio de la Peña Pineda (1905-2001), de Madrid, Juan Martínez García (1913-1981), de Murcia, Pascual Ipiens Lacasa (1904-1991), de Pamplona, Jacinto Navas González (1898-1985), de Córdoba y, por 
último, José Martín Vivaldi (1903-1986), de Granada. Es elegido Alfonso de la Peña jefe del servicio de Urología del Hospital Clínico de Madrid, delegado español en la SIU al cesar el Dr. Pulido, quien, con su brillante gestión, había logrado, por su intervención personal y directa, llevar el congreso a la ciudad de Barcelona al igual que el número de miembros españoles ascendiera a cuarenta.

IX congreso, Nueva York, 1952, los días 15 a 18 de septiembre, bajo la presidencia del Dr. G. G. Smith, con la asistencia de los delegados de dieciséis países y de los españoles Antonio Puigvert, Alfonso de la Peña y Tomás de la Maza, quienes participaron en la discusión de la ponencia «Tratamiento médico de la tuberculosis renal»; Antonio Puigvert presentó una película sobre «Diversas técnicas de resección parcial de la vejiga» y Alfonso de la Peña otra sobre "Cistectomía total con implantación de los uréteres en sigma». Como novedad se expusieron tres diferentes modelos de riñón artificial. El Dr. Alfonso de la Peña fue reelegido delegado del comité español y se nombraron vocales a Julio Picatoste Picatoste y Vicente Company, asemás de cuatro nuevos socios, José Luís Insausti Cordón (1917-1989), Julio Picatoste Patiño, Francisco Romero Aguirre (1918-2006) y Angulo Cuesta. Como anécdota referir que la sesión inaugural tuvo lugar en uno de los salones del Hotel

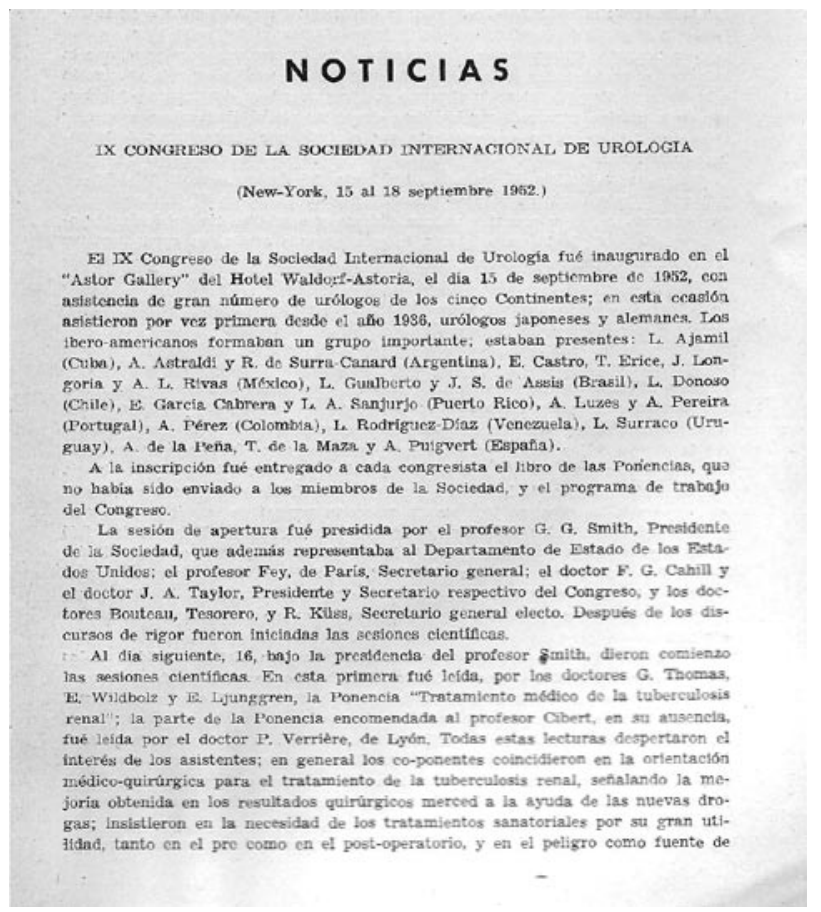

FIGURA 12. IX Congreso de SIU en Nueva York, 1952. Arch. Esp. de Urol. VIII (4): 367, 1952.
Waldorf Astoria decorado con las pinturas del español José María Sert y Badía (1876-1945).

$\mathrm{X}$ congreso, Atenas 1955, del 10 al 18 de abril; bajo la presidencia del Dr. G. Smith y del profesor Spyridion Oeconomos en el palacio de Zappion, congregó a un buen número de urólogos, muchos de ellos de los países del telón de acero y de los españoles únicamente los catalanes Salvador Gil Vernet, Francisco Serrallach, José María Lucena y Mariano Bretón. Alfonso de la Peña y Fernando de Castro, catedrático de Anatomía de la Universidad Complutense, presentaron su ponencia «Conceptos histopatológicos referentes al tratamiento del cáncer de próstata» que fue leída por Gil Vernet; el resto de las temas fueron «Angiografía renal» y "Tratamiento postoperatorio de la litiasis urinaria». Se mantuvo a los componentes del comité directivo español y fueron nombrados miembros numerarios Mariano Rabadán, de Madrid, Ramón Sánchez Parra (1896-1982), de Murcia, José María Martínez Sagarra (n. 1906), de Valladolid, Luís de la Torriente Rivas (n. 1905), de Santander, y Antonio Cols Baqué y José María Bartrina Calvo, de Barcelona.

XI congreso, Estocolmo, 1958, durante los días 25 de junio al 1 de julio (Figura 13), presidido por el responsable de la Sociedad, el británico A.

\section{Société internationale}

d'Urologie

STOCKHOLM, SUÊDE 25-30 JUIN 1958

TOME I.RAPPORTS

$*$

PRÊSIDENT: JOHN HELLSTRÖM

SECRETAIRE GENERAL: GUSTAV GIERTZ

FIGURA 13. Libro de Actas del XI Congreso, Estocolmo, 1958. 


\section{CONGRÈS DE LA}

\section{Société}

\section{internationale}

\section{d'Urologie}

RIO DE JANEIRO. BREESIL, 24-29 JUILLET 1961

TOME II

Président: A. FIGUEIREDO BAENA

Secrétaire-Général: J. SILVA DE ASSIS

FIGURA 14. Libro de Actas del XII Congreso, Río de Janeiro, 1961.

Clifford-Morson, y por el profesor Jonh Helström, de la asociación sueca. Salvador Gil Vernet realizó una notable exposición sobre «Vejiga neurógena», tema en el que también participaron Luis Cifuentes y Francisco Serrallach; hubo aportaciones a la ponencia sobre «Utilización de injertos intestinales en Urología» por los españoles Alfonso de la Peña, Francisco Serrallach, Antonio Puigvert, Luís Batalla Sabaté y José María Gil-Vernet; destacaron las películas de Alfonso de la Peña sobre «Acceso coxianal para la cirugía de la próstata y vesículas seminales», «Plastias intestinales» de José María Gil-Vernet y el trabajo del Dr. Alcalá Santaella, de Valencia, sobre «Cirugía de la hidronefrosis»; el último motivo de discusión, «Hematuria renal esencial», contó con una amplia intervención española. Fueron admitidos nuevos miembros: Rafael Benlloch Navarro, de Valencia, Miguel García Lasaleta, José María Gil-Vernet Vila, Nicolás Peña Martínez (1906-1991), de Vigo, Julio Pérez Irezabal, de Bilbao, Luis Resel Maceira (n. 1908), de Madrid, el sevillano Eduardo Ruiz de Velasco Mejía (1901-1979) y José Gabriel Sopeña Campello y Manuel Villar Blanco, de Santiago de Compostela. Los miembros del Comité Español consiguieron que algunos países hispanoamericanos, que no tenían representación, contasen en adelante con un delegado, la composición del nuevo comité quedó constituida por

\section{$\mathrm{XIII}^{\mathrm{e}}$ CONGRÈS DE LA}

\section{Société internationale}

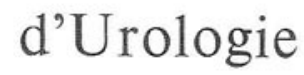

LONDRES, 29 AOÚT -5 SEPTEMBRE 1964

VOLUME $1 \cdot$ REPORTS

\author{
Published by \\ E. \& S. LIVINGSTONE LTD. \\ EDINBURGH AND LONDON \\ 1964
}

FIGURA 15. Libro de Actas del XIII Congreso, Londres, 1964.

Luis Cifuentes y vocales Alfonso de la Peña y Enrique Pérez Castro. Como nota negativa, el idioma español junto con el italiano, ambos oficiales, no dispusieron de traducción simultánea en las discusiones y deliberaciones $y$, ante la reclamación española, los organizadores se justificaron por no disponer de más cabinas de traducción simultánea y las que tenían fueron destinadas al inglés, francés y alemán, por el mayor número de congresistas inscritos.

XII congreso, Río de Janeiro, 1961, los días 24 a 29 de julio (Figura 14), presidido por A. Clifford Morson y el profesor F. Baena, con la asistencia de unos cuatrocientos urólogos, la mayoría Hispanoamericanos. Acudieron únicamente tres españoles, que presentaron comunicaciones a las ponencias, Alfonso de la Peña, «Ureterolitectomía transvaginal», «Rectocistoplastia y extrofia vesical» y «Punción transcutánea del riñón», Puigvert Gorro, «Ureterectomías terminales con ureterocistorrafia y con ureterorrafias término-terminal» $y$ «Posibilidades de la exéresis parcial renal por tumor», y Antonio Moya Prats, "Contribución al estudio del tratamiento de la disuria prostática con extractos acuosos de próstatas de animales sanos y púberes», "Evolución histológica estudiada por biopsia percutánea perineal» y «Cinematografía radiográfica». Fue elegido presidente de la Interna- 
cional al italiano profesor Pisani y se designó delegado español al Dr. Alfonso de la Peña.

XIII congreso, Londres, 1964, del 29 de agosto al 5 de septiembre, (Figura 15) presidido por el Dr. Pisani, de la internacional, y por Sir Eric Riches, del congreso, y como secretario D. Innes Williams. Asistieron los españoles Alfonso de la Peña, delegado español, $y$, entre otros, Luís Cifuentes, Enrique Pérez Castro, Julio Pérez Irezábal, Julio Picatoste, Ignacio Ponce de León, Francisco Serrallach, Carlos del Río y Rey Stolle y José María Junquera (1918-1997); el Dr. de la Peña mostró en las exhibiciones su colección de tumores ureterales, perfectamente conservados y estudiados, con su histología, iconografía, etc. y leyó la ponencia del Dr. Benlloch Navarro, que no pudo acudir, sobre "Pronóstico de los tumores testiculares en relación con su histopatología» (Figura 16), además de su trabajo sobre "Coriocarcinoma de testículo: dos casos». Presentaron comunicaciones a la ponencia sobre "Carcinoma de vejiga» los Drs. Alfredo Tramoyeres, de Valencia, "Neovejiga rectal con colostomía perineal», Francisco Romero Aguirre, «Colocistoplastia, neovejiga rectal y colostomía, viscerotomía pelvica y ureterectomía transentérica en carcinoma de vejiga», y Puigvert, Solé Balcells y Gosálvez, «Resultados tardíos del tratamiento por cirugía y agentes físicos». Se proyectaron películas de

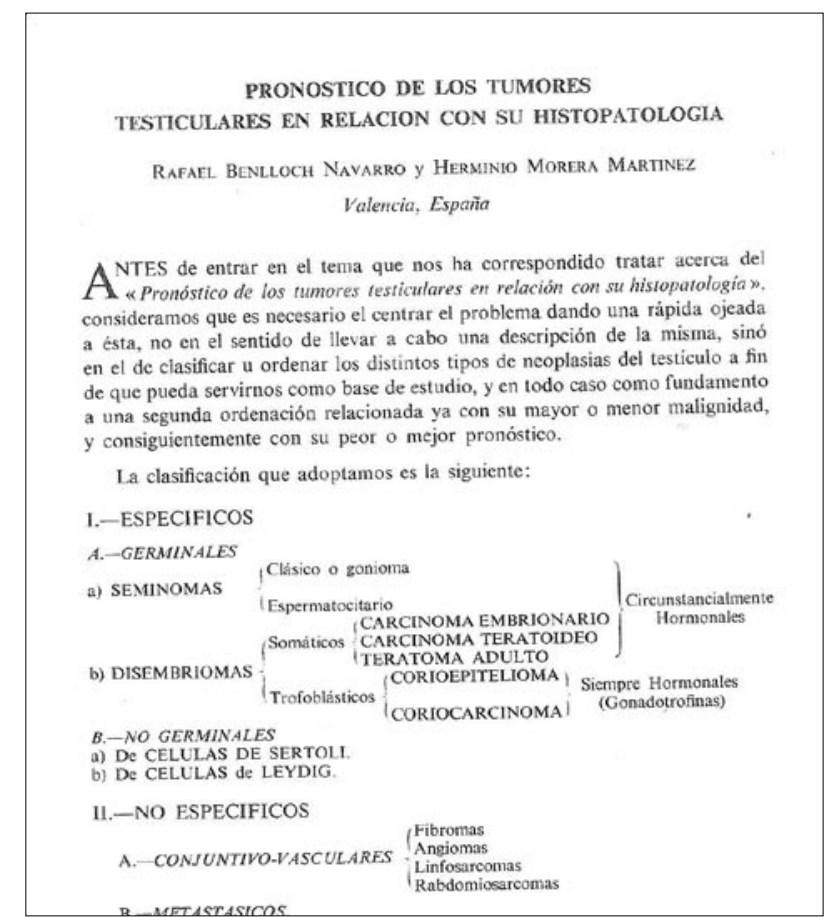

FIGURA 16. Ponencia del Dr. Benlloch Navarro, de Valencia, «Pronóstico de los tumores testiculares en relación con su histología».
Pérez Castro, "Tratamiento quirúrgico de la extrofia vesical», y de José María Gil Vernet, «Nueva cirugía en los cálculos renales».

En la asamblea general se decidió que la elección o reelección de los delegados se llevaría a cabo seis meses después de la celebración del congreso y se creó la figura del vicedelegado o delegado adjunto para poder cubrir la posible ausencia del titular; por ello, en enero de 1965, se reunió en Madrid el capítulo español con la asistencia de 25 de sus miembros para votar al nuevo comité nacional, se nombró delegado a Enrique Pérez Castro, vicedelegado a Luis Cifuentes Delatte y vocales a Francisco Romero Aguirre y Luís Batalla Sabaté.

XIV congreso, Munich, 1967, del 9 al 14 de julio, bajo la presidencia del Dr. L. Pisani y del Dr. May, ante la renuncia del profesor Boeminghaus por enfermedad. Se celebró en los salones reconstruidos del Nationaltheater, los temas tratados fueron «Trasplante renal humano», «Hipertensión arterial de ori-

\section{XV' CONGRÈS}

\section{de la SOCIÉTÉ}

INTER N ATIO NALE D'UROLOGIE

Tokio 12-18 Juillet 1970

\section{TO M E 1 RAPPORTS}

Président: Tokuji ICHIKAWA Secrétaire général : Hisao TAKAYASU

\section{0}

FIGURA 17. Libro de actas del XV Congreso, Tokio, 1970. 


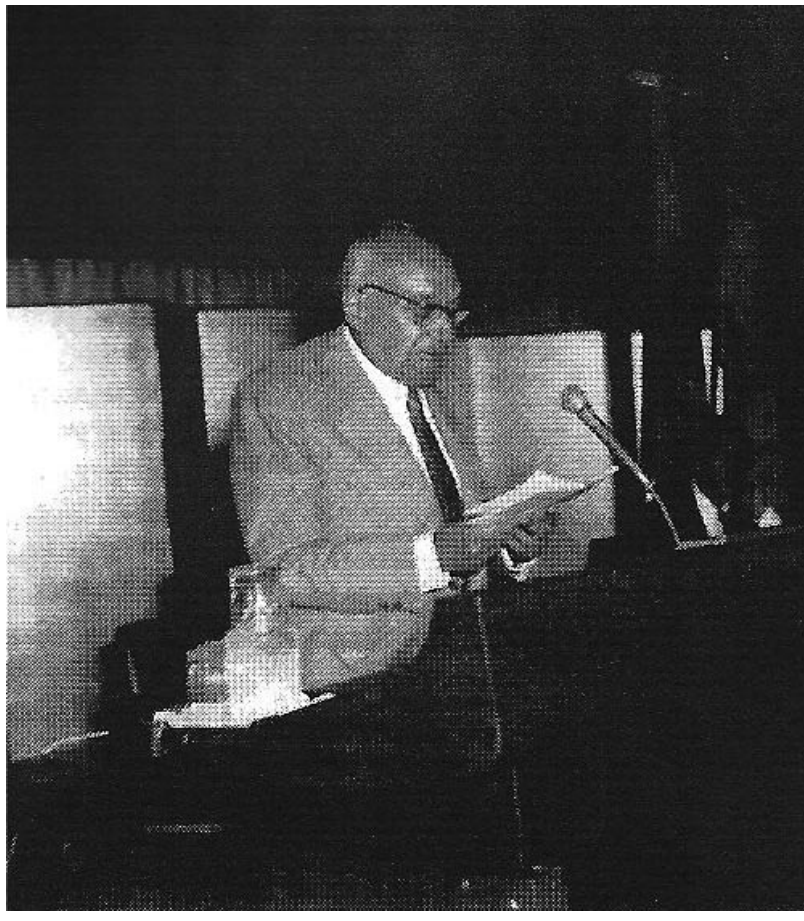

FIGURA 18. El Dr. Gil Vernet lee su discurso como presidente del XV Congreso, Tokio, 1970.

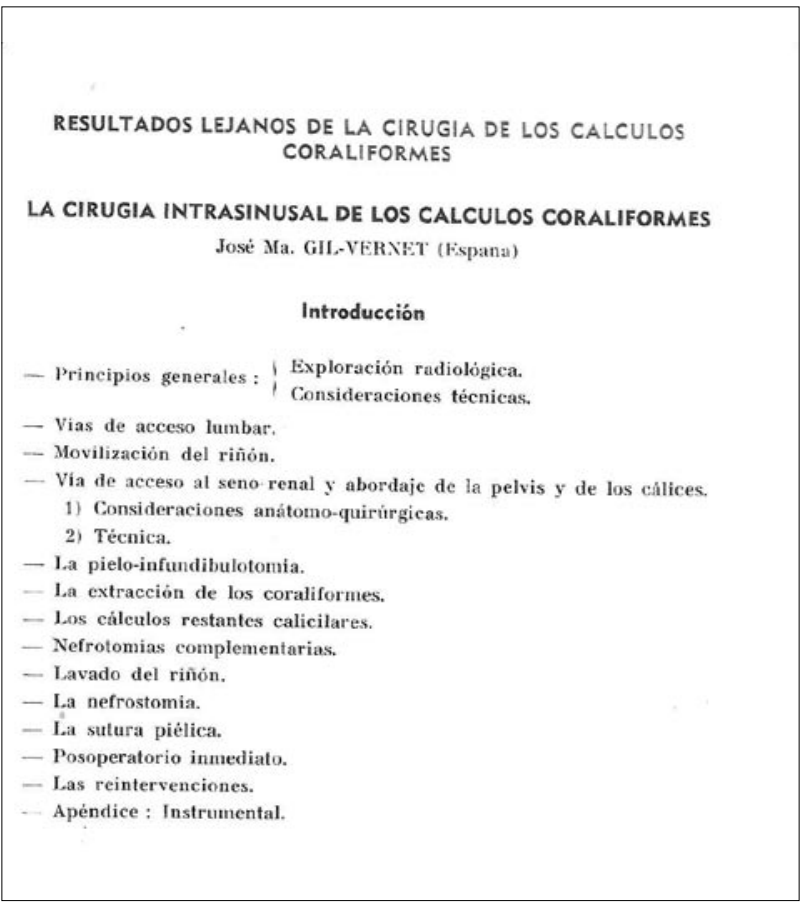

FIGURA 19. Ponencia del Dr. José María Gil Vernet, "La cirugía intrasinusal de los cálculos coraliformes», XV Congreso, Tokio, 1970. gen renal», «Pielonefritis crónica», y por vez primera, se desarrollaron dos mesas redondas, una sobre «Disolución de cálculos urinarios» y sobre «Traumatismos uretrales». Como dato relevante señalamos la presentación de la fuente de luz fría para la endoscopia, por la casa Storz. La asistencia española fue abundante sin que dispongamos de la relación de sus aportaciones.

El Dr. Salvador Gil Vernet fue elegido por unanimidad, tras la votación preceptiva, presidente de la SIU y obtuvo para España cuatro nuevos socios. Tras el congreso, el delegado del capítulo español, Dr. Pérez Castro, convocó en Madrid a los urólogos españoles para cubrir siete vacantes, así el 21 de octubre de 1969 fueron admitidos, tras el escrutinio de los votos emitidos por los miembros activos, los Drs. Juan Montero Díez, Andrés Sánchez Salvador (19222006), Carlos Alférez Villalobos (1927-2007), Pedro González Páramo (1929-1999), Rafael Gosálvez Jordá, Amalio Pérez Coutiño y Aurelio Usón Calvo, para su posterior refrendo en el Congreso de Tokio y se aceptó la propuesta de presentar a España como sede para el Congreso de 1973.

XV congreso, Tokio, 1970, del 12 al 18 de julio (Figura 17), presidido por el Dr. Salvador Gil Vernet (Figura 18), a quien le fue prorrogado su mandato por un nuevo periodo de tres años y el Dr. Tokuji Ichikawa, del comité local. Presentó una ponencia José María Gil Vernet sobre «La cirugía intrasinusal de los cálculos coraliformes» (Figura 19), extraordinario trabajo en el que recorre las vías de acceso lumbar y del seno renal y su nueva técnica quirúrgica de infundibulotomía para la extracción de los cálculos coraliformes, acompañada de abundante iconografía, sobre la que proyectó una película $y$, además, otras sobre "Cirugía de la hipertensión vásculo renal», «Nuevo método de de protección renal en la cirugía renovascular», "Cinerradiografia del trasplante renal por medio de la anastomosis pielo-piélica», "Cirugía de la glándula suprarrenal», «Trasplante de testículo» y «Ruta de acceso al riñón en la cifoescoliosis», los Drs. Solé Balcells y Gosálvez expusieron su comunicación sobre «Válvula ureteral y divertículo para ureteral».

Se le concedieron a España cinco nuevos puestos y fueron elegidos, en noviembre de 1971, entre las candidaturas presentadas, Antonio Allona Moncada (1921-1995), de Málaga, Manuel Peláez Redondo, de Salamanca, Felipe Alcalá Santaella (1927-1977), de Valencia, Ramón Sánchez Parra Jaén (1927-1998), de Murcia, Fernando Martín Laborda, de Madrid, Antonio Valverde Mazuelas, de Córdoba y José María Abaitúa Bilbao, de Santander. 
XVI congreso, Ámsterdam, 1973, del 1 al 6 de julio (Figura 20), presidido por el profesor Salvador Gil Vernet y P. J. Donker. Presentó una ponencia D. Salvador Gil Vernet sobre «Origen y desarrollo del cáncer de la próstata» (Figura 21) y fueron relatores A. Puigvert, J. Vicente y F. Jiménez con «Nuestra experiencia en el tratamiento combinado del carcinoma de la próstata», I. Ponce de León, S. Marina y E. Zungri, «Estudio seminológico y radiográfico en las vesiculitis», A. Moya, E. Zungri, S. Vives, N. Mallo y J. Vicente, "Diagnóstico de la incontinencia urinaria femenina», I. Ponce de León, "Denervación en la incontinencia neurogénica con vejiga no inhibida», y Tramoyeres Cases, «La resección transuretral del esfínter uretral externo en pacientes con vejiga neurógena hipotónica», además de otras dieciséis comunicaciones libres.

En la reunión del capitulo español, el 9 de febrero de 1974, el delegado Dr. Pérez Castro hace un llamamiento en defensa del mantenimiento del idioma español en la Sociedad Internacional ya que, al cese como presidente de Gil Vernet, existen manio-

XVI' CONGRÈS

de la

SOCIÉTÉ

INTER N ATIO N ALE

D'UROLOGIE

Amsterdam 1-6 Juillet 1973

TO M E 1

RAPPORTS

Président : P.J. DONKER

Secrétaire général : H.W. ten CATE

1973 bras para que deje de ser oficial. En el mes de abril se eligen los miembros seleccionados por votación para ocupar las plazas vacantes, cinco de nueva creación, José María Pomerol Serra (1920-2004) y Narciso Serrallach Milá, de Barcelona, Gerardo Server Falgas (1928-1999) de Murcia, Pascual Ipiens Lacasa (1904-1991) de Pamplona, Enrique Acero Santa María (1911-2000), Ramón Valdés Gómez, Benito Escudero Solano, Vicente Borobia López, Saturnino Achiaga y Remigio Vela Navarrete de Madrid.

XVII congreso, Johannesburgo, 1976, del 25 al 30 de julio, (Figura 22) presidido por J. K. Lattimer, de la Internacional y J. D. Joubert, del comité local. Se trataron los temas "Tumores renales», "Vejiga neurógena» y "Esterilidad masculina», sobre el que presentaron una ponencia los Drs. Pedro G. Páramo (1929-1999) y Luis Resel Estévez (1936-2005), «Resultados del tratamiento de la esterilidad masculina» (Figura 23); participaron en las mesas redondas el Dr. Insausti Cordón en «Los isótopos en Urología» y José María Gil Vernet en la de «Tratamiento de los traumatismos de uretra».

La asistencia de los miembros nacionales fue escasa, el delegado Dr. Pérez Castro informa, ya en Madrid, de la gran atención mostrada hacia los españoles que lamentablemente no fue correspondida

ORIGEN Y DESARROLLO DEL. CANCER DE LA PROSTATA

Professeur S. GIL VERNET

Conocer y precisar el origen y el desarrollo del cáncer de la prós. ata además del interés cientifico, tiene una gran importancia práctic n clinica, ya que constituye la base para sentar las indicaciones terapéuticas adecuadas, a las diferentes etapas de su evolución.

Otros colegas expondrán con precisión los diferentes tipos de áncer de la próstata, así como los llamados cánceres ocultos o carcinoides. Sólo indicaré aquí, que el cáncer de observación corriente mayor e menor grado de diferenciación.

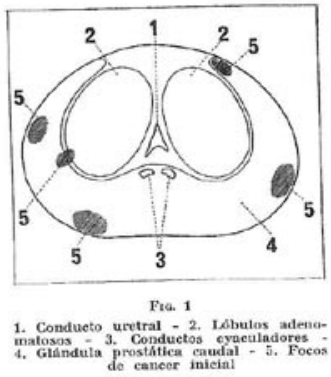

FIGURA 21. Ponencia del Dr. Salvador Gil Vernet «Desarrollo del Cáncer de próstata», XVI Congreso,

Ámsterdam, 1973.
FIGURA 20. Libro de actas del XVI Congreso, Ámsterdam, 1973. 


\section{XVII'CONGRÈS}

\author{
de la \\ SOCIÉTÉ
}

INTER N ATIO NALE

D'UROLOGIE

Johannesburg 25 - 30 juillet 1976

\section{TOM E 1 \\ RAPPORTS}

Président: J.D. JOUBERT

Secrétaire général: P.J.M. RETIEF

\section{6}

FIGURA 22. Libro de actas del XVIII Congreso, Johannesburgo, 1976.

ya que la mayoría de las presidencias y de participantes en mesas redondas debieron ser sustituidos por inasistencia de los españoles invitados. Se suscitó en la reunión de la Asamblea el tema de mantener los cinco idiomas oficiales lo que fue defendido y ganado por la gran defensa que hizo el Dr. Pérez Castro quien tampoco estaba de acuerdo con la propuesta de la jubilación automática a los setenta años. Nos fueron concedidas cinco nuevas plazas.

XVIII congreso, París, 1979, del 24 al 29 de junio (Figura 24), presidido por el profesor René Küss quien en su discurso inaugural hizo una importante $y$ acalorada defensa del francés ante la pretensión de dejar al idioma inglés como única lengua en los Congreso de la Sociedad, Arch. Esp. Urol; 1979; XXXII (5): 489-491. Se discutieron los temas «Epidemiología de la litiasis», "Terapia inmunológica en Urología», «Hidrodinamia del uréter dilatado» y hubo dos mesas redondas sobre "Cirugía extracorpórea del riñón y cirugía intrarrenal bajo hipotermia» y «Tera-

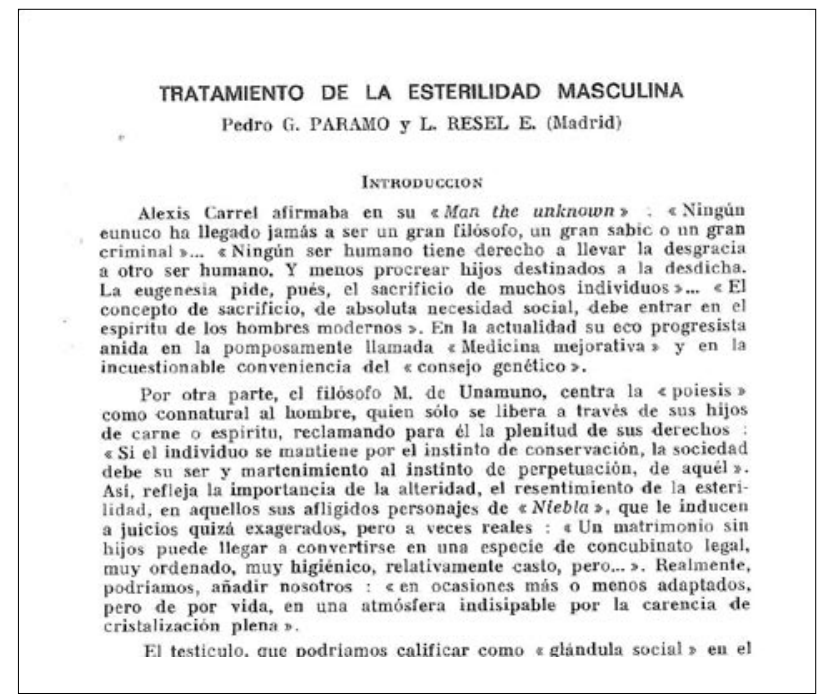

FIGURA 23. Ponencia de los Drs. Páramo y Resel «Resultados del tratamiento de la esterilidad masculina», XVIII Congreso, Johannesburgo, 1976.

pia por oclusión embólica arterial». Presentaron los urólogos españoles 37 comunicaciones libres de las que José María Gil Vernet expuso dieciocho, Alférez Villalobos, seis, Solé Balcells y colaboradores y Resel Estévez, dos, y una, Martínez Piñero, García Cuerpo, Insausti Cordón, Junquera Vila, Nogueira March, Vela Navarrete, Cifuentes Delatte, Martín Vivaldi y Díez Yanguas.

Tras el congreso se reunió en Madrid el capítulo español de la Sociedad Internacional, convocado por el delegado Dr. Pérez Castro, informó de la aprobación de un nuevo estatuto cuyo contenido se recoge en Arch. Esp. Urol; 1979; XXXII (4): 409416 , y comentó sus modificaciones como la creación de la figura del miembro senior para los mayores de 65 años, los cuales no pueden optar a desempeñar cargos directivos, por lo que le corresponde cesar en el puesto, es sustituido por Francisco Romero Aguirre, catedrático de Urología de la Universidad de Zaragoza y son elegidos vocales Martínez Piñero, Montero Gómez, Solé Balcells y Usón Calvo.

XIX congreso, San Francisco, 1982, del 5 al 10 de septiembre (Figura 25), presidido por el de la Sociedad Rene Küss y del congreso Emil A. Tanagho, entre los vicepresidentes de la Internacional figura José María Gil-Vernet. Se discutieron los temas: «Relación coste y eficacia de las investigaciones en Urología», "Modificaciones urodinámicas del apara- 


\section{CONGRÈS}

de la

SOCIÉTÉ

INTERNATIONALE

D'UROLOGIE

PARIS 24-29 juin 1979

TOME 2

DISCUSSIONS DES RAPPORTS

TABLES RONDES

COMMUNICATIONS LIBRES

Président: René KÜSS

Secrétaire général: Alain JARDIN

1979

FIGURA 24. Libro de actas del XVIII Congreso, París 1979.

to urinario inferior inducidas por drogas», «Patología obstructiva cérvico uretral en el niño», "Uretrotomía o uretroplastia» e «Infecciones urinarias recidivantes de la mujer». Hubo numerosas aportaciones españolas.

XX congreso, Viena, 1985, del 23 al 28 de junio, presidido por Rene Küss. Se desarrollaron las ponencias «Diagnóstico de terapia con ondas ultrasónicas», "Tratamiento de urgencia de las lesiones del aparato urinario», «El tumor vesical, pronóstico y terapia» y las mesas redondas "Los rayos láser en Urología» y «El tratamiento del tumor de testículo». No hemos logrado obtener datos de la presencia hispana; fue elegido delegado español, Ignacio Ponce de León.

XXI congreso, Buenos Aires, 1988, del 9 al 14 de octubre (Figura 26), estuvo presidido por el Dr. W. Gregoire de la Internacional y A. J. Claret de la Argentina, entre los vicepresidentes figura el

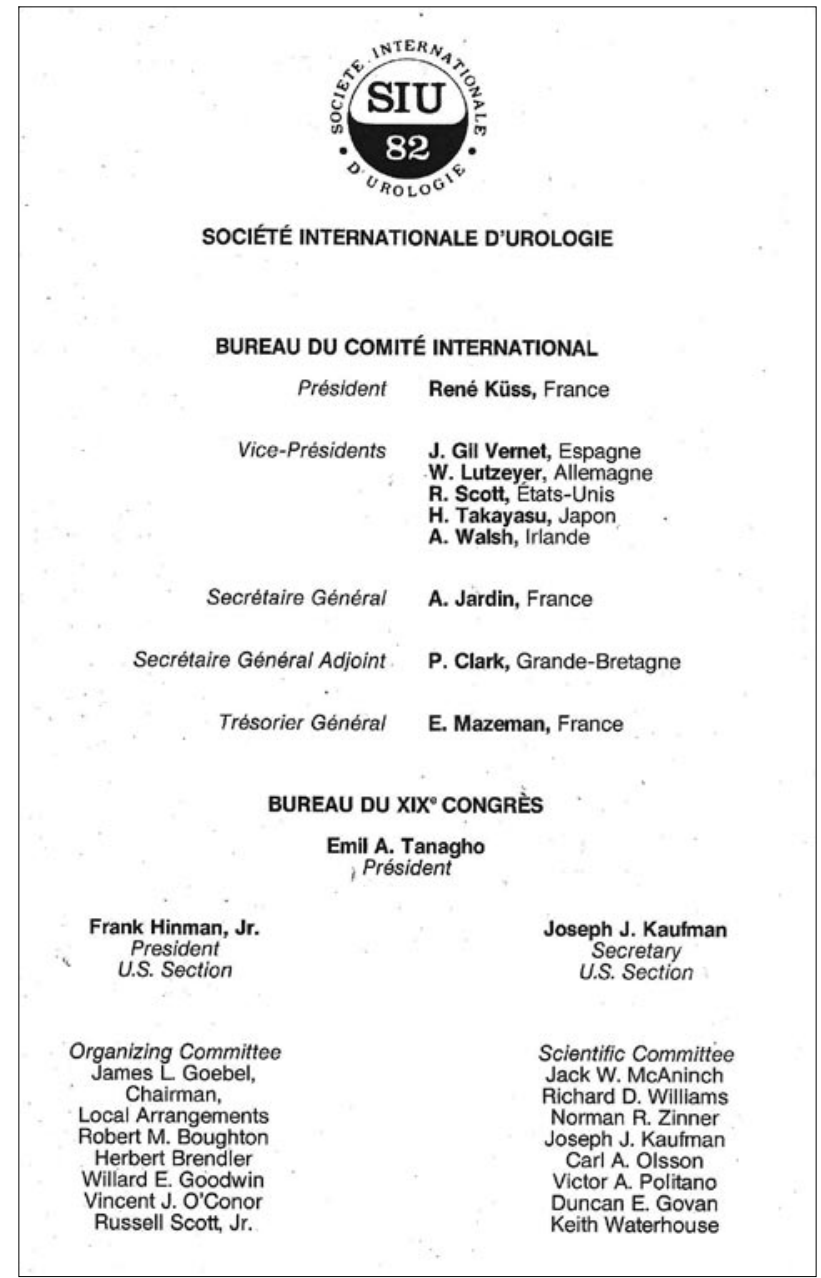

\section{FIGURA 25. Comité organizador del XIX Congreso,} San Francisco, 1982.

español Aurelio Usón, las ponencias versaron sobre «Tratamiento no quirúrgico de la litiasis renal», en el que participó el Dr. Pérez-Castro Ellend con «Tratamiento endoscópico de la litiasis», «Impotencia» y «Evaluación de los resultados de la inmunoterapia en tumores urogenitales», el Dr. Jiménez Cruz participó con el tema "Ordenadores en Urología» y el Dr. Ponce de León presidió la mesa sobre «Resonancia magnética en Urología». Las sesiones se desarrollaron en el Hotel Sheraton y la asistencia hispana fue muy abundante con más de 200 inscritos, que presentaron 130 comunicaciones, lo que, junto con la tentadora oferta hecha por el delegado español Dr. Ponce de León, redundó en beneficio de la candidatura de la ciudad de Sevilla como sede del próximo congreso frente a las opciones favoritas de Florencia y Estrasburgo.

XXII congreso, Sevilla, 1991, del 3 al 7 de noviembre (Figura 27) enmarcado dentro de los actos 
conmemorativos del $\mathrm{V}$ centenario del descubrimiento de América. Presidido por el Dr. Ignacio Ponce de León Castell y el de la Internacional Dr. A Wals, el secretario general Dr. Mazeman y el del congreso Marceliano García Pérez, vicepresidentes José A. Martínez-Piñero y Francisco J. Solé Balcells.

La asistencia fue numerosa con unos tres mil urólogos, de los que 400 eran españoles, así como la participación científica con 927 trabajos admitidos, de los que 129 eran nacionales; se debatieron veinte temas diferentes fueron distribuidos pasa su exposición en 12 sesiones orales, 28 de póster y 19 de videos que ocuparon siete salas durante los cuatro días del congreso.

En el simposio "Tratamiento no operatorio de la hipertrofia prostática benigna», que fue el tema que más comunicaciones tuvo. Participó como ponente Fernando Algaba, anatomopatólogo de la Fundación Puigvert, con «Fisiopatología de la hipertrofia benigna», en el de «Incontinencia de orina», Juan

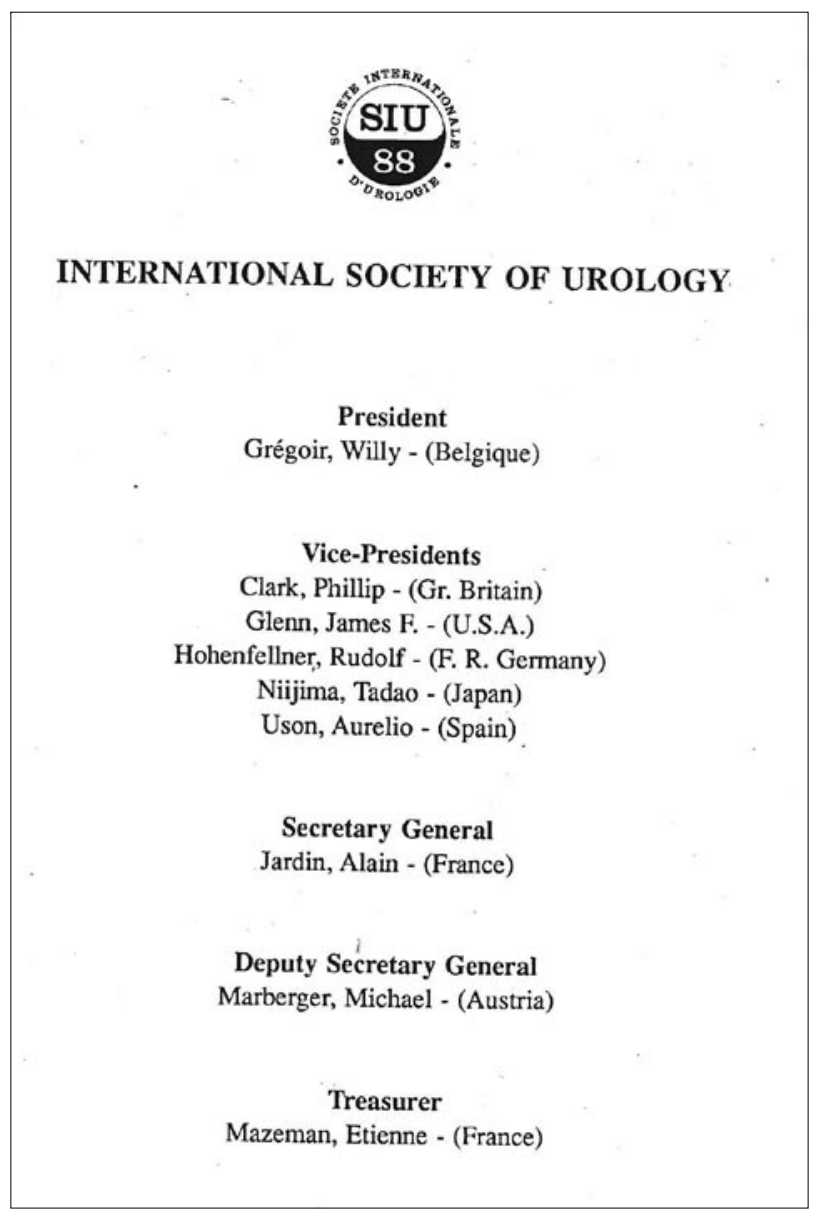

FIGURA 26. Libro de actas del XXI Congreso, Buenos Aires, 1988.
Conejero Sugrañes expuso la «Evaluación urodinámica», y en el tercero «Evaluación de la quimioterapia en el cáncer de vejiga», participaron Joaquín Carballido y Álvarez de Mon con estudios sobre el efecto del interferon alfa en el cáncer vesical. Actuaron como moderadores y dirigieron mesas de discusión otros cuarenta urólogos españoles. Descollaron las aportaciones hispanas sobre trasplante renal, incontinencia urinaria, los diversos métodos de tratamiento de la litiasis urinaria y de cirugía mínimamente invasiva. El número de miembros españoles activos en la Sociedad era de 62 y se amplió en otros veinte más.

XXIII congreso. Sydney, 1994, del 18 al 22 de septiembre. Presidido por el de la Internacional, el norteamericano J. Glenn. Únicamente conocemos la asistencia de los Drs. Ponce de León Castell y Ponce de León Roca que presentaron la comunicación «Involución de la hipertrofia prostática en pacientes tratados con bloqueo epidural sacro».

XXIV congreso. Montreal, 1997, a primeros del mes de septiembre. Presidido por el de la Internacional profesor alemán R. Hohenfellner. A partir de este año desaparece el sistema de cuotas por país

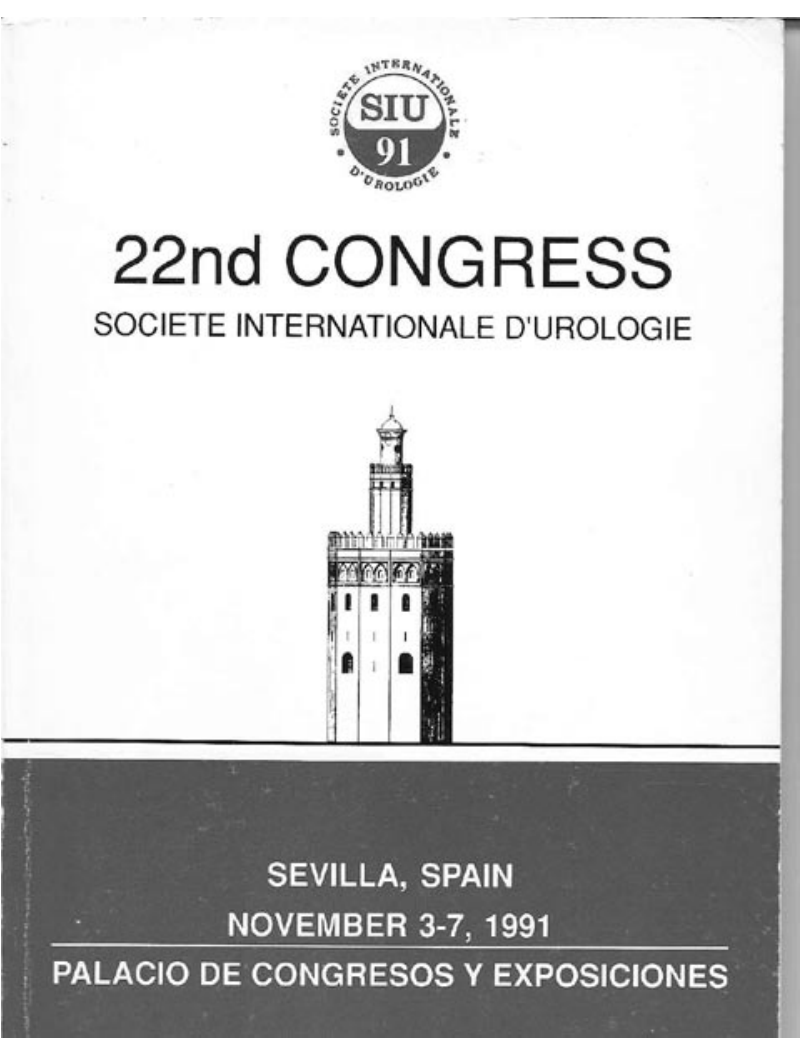

FIGURA 27. Libro de actas del XXII Congreso, Sevilla 1991. 


\section{TABLA I.}

\begin{tabular}{|c|c|}
\hline & CONGRESOS DE LA ASOCIACIÓN INTERNACIONAL DE UROLOGÍA. \\
\hline I & 1908. París, 30 de septiembre a 3 de octubre \\
\hline II & 1911. Londres, del 24 al 28 de julio \\
\hline III & 1914. Berlín \\
\hline \multicolumn{2}{|r|}{ CONGRESOS DE LA SOCIEDAD INTERNACIONAL DE UROLOGÍA EN EL SIGLO XX. } \\
\hline I & 1921. París, del 5 al 8 de julio \\
\hline$\|$ & 1924. Roma, del 24 al 26 de abril \\
\hline III & 1927. Bruselas, del 3 al 6 de agosto \\
\hline IV & 1930. Madrid, 7 al 12 de abril \\
\hline $\mathrm{V}$ & 1933. Londres, 11 al 15 de julio \\
\hline VI & 1936. Viena. Agosto \\
\hline VII & 1947. Saint Moritz, del 25 al 28 de agosto \\
\hline VIII & 1949. Barcelona, del 20 al 23 de septiembre \\
\hline IX & 1952. Nueva York, del 15 al 18 de septiembre \\
\hline$x$ & 1955. Atenas, del 10 al 18 de abril \\
\hline $\mathrm{XI}$ & 1958. Estocolmo, del 25 de junio al 1 de julio \\
\hline $\mathrm{XII}$ & 1961. Río de Janeiro, del 24 al 29 de julio \\
\hline XIII & 1964. Londres, del 29 de agosto al 25 de septiembre \\
\hline XIV & 1967. Munich, del 9 al 14 de julio \\
\hline$X V$ & 1970. Tokio, del 12 al 18 de julio \\
\hline $\mathrm{XVI}$ & 1973. Ámsterdam, del 1 al 6 de julio \\
\hline $\mathrm{XVII}$ & 1976. Johannesburgo, del 25 al 30 de julio \\
\hline $\mathrm{XVIII}$ & 1979. París, del 24 a 29 de junio \\
\hline $\mathrm{XIX}$ & 1982. San Francisco, del 5 al 10 de septiembre \\
\hline$X X$ & 1985. Viena, del 23 a 28 de junio \\
\hline$X X I$ & 1988. Buenos Aires, del 9 al 14 de octubre \\
\hline XXII & 1991. Sevilla, del 3 al 7 de noviembre \\
\hline$X X I I I$ & 1994. Sydney, del 18 al 22 de septiembre \\
\hline XXIV & 1997. Montreal, 2 al 8 de septiembre \\
\hline$X X V$ & 2000. Singapur, del 29 de octubre al 2 de noviembre \\
\hline
\end{tabular}

TABLA II. CARGOS OSTENTADOS POR URÓLOGOS ESPAÑOLES.

- Leonardo de la Peña Díaz, presidente del IV congreso, Madrid, 1930

- Salvador Gil Vernet, presidente del VIII congreso, Barcelona 1949

- Salvador Gil Vernet, presidente de la Sociedad Internacional de 1967 a 1973

- José María Gil-Vernet, vicepresidente del Comité internacional en 1982

- Aurelio Usón Calvo, vicepresidente del Comité internacional de 1988-1991

- Ignacio Ponce de León, presidente del XXII congreso, Sevilla, 1991 
1908 Enrique Lluria Despau

1921 José María Bartrina Thomás

1927 Isidro Sánchez Covisa

1933 Pedro Cifuentes Díaz

1947 Ángel Pulido Martín

1949 Alfonso de la Peña Díaz

1958 Luis Cifuentes Delatte

1961 Alfonso de la Peña Díaz

1964 Enrique Pérez Castro

1979 Francisco Romero Aguirre

1985 Ignacio Ponce de León Castell

1991 Marceliano García Pérez $\begin{array}{ll}\text { 1908-1914 F. Guyon (Francia) } \\ 1921-1927 & \text { H. Fenwick (Gran Bretaña) }\end{array}$

1927-1936 E. L. Keyes (Norteamérica)

1936-1940 F. Legueu (Francia)

1947-1955 G. G. Smith (Norteamérica)

1955-1961 A. Clifford-Morson (Gran Bretaña)

1961-1967 L. Pisani (Italia)

1967-1973 S. Gil Vernet (España)

1973-1979 J. K. Latimer (Norteamérica)

1979-1985 R. Küss (Francia)

1985-1988 W. Gregoire (Bélgica)

1988-1991 A. Walsh (Irlanda)

1991-1994 J. Glenn (Norteamérica)

1994-1997 R. H. Ohenfellner (Alemania)

1997-2000 Y. Aso (Japón)

\section{TABLA V. PONENTES ESPAÑOLES.}

Pedro Cifuentes Díaz, «Resultados lejanos de las operaciones de litiasis renal», Roma, 1924.

Isidro Sánchez Covisa, «Etiología y tratamiento de la hidronefrosis», Madrid, 1930.

Ángel Pulido Martín, «Antisépticos urinarios», Madrid, 1930.

Eduardo Perarnau, «Infecciones colibacilares del aparato urinario», Madrid, 1930.

Salvador Pascual Ríos, «Tumores de la pelvis renal y uréter», Londres, 1933.

Salvador Gil Vernet, «Tratamiento de las obstrucciones del cuello vesical», Barcelona, 1949.

Alfonso de la Peña y Fernando de Castro, «Conceptos histopatológicos referentes al tratamiento del cáncer de próstata», Atenas, 1955.

Rafael Benlloch Navarro, «Pronóstico de los tumores testiculares en relación con su histopatología», Londres, 1964.

Salvador Gil Vernet, «Origen y desarrollo del cáncer de próstata», Ámsterdam, 1973.

Pedro G. Páramo y Luis Resel Estévez, «Resultados del tratamiento de la esterilidad masculina», Johannesburgo, 1976.

Enrique Pérez-Castro Ellendt, «Tratamiento endoscópico de la litiasis», Buenos Aires, 1988.

Fernando Jiménez Cruz, «Ordenadores en Urología», Buenos Aires, 1988.

Fernando Algaba Arrea «Fisiopatología de la hiperplasia benigna de próstata», Sevilla, 1991.

Juan Conejero Sugrañes «Evaluación hidrodinámica de la incontinencia urinaria», Sevilla, 1991.

Joaquín Carballido «Manejo inmunológico del cáncer vesical con interferon alfa», Sevilla, 1991.

M. Álvarez-Mon Soto «Efecto inmunomodulador del interferón alfa-2b en la muerte natural de la célula y de los linfocitos T de pacientes con carcinoma transicional de vejiga», Sevilla, 1991. 
para la admisión de nuevos socios y se deja libre su ingreso, la presentación de trabajos puede hacerla cualquier urólogo. La Sociedad, en este momento, cuenta con unos cuatro mil socios de cien países y la sede central se encuentra ubicada en la ciudad de Montreal, en Canadá. La asistencia y presentación de comunicaciones por parte española fue alta. Fue nombrado presidente de la Sociedad Internacional al japonés Y. Aso.

XXV congreso. Singapur, 2000, del 29 de octubre al 2 de noviembre. Último congreso del siglo XX del que no hemos conseguido disponer de las actas ni obtener datos sobre la presencia de españoles ni sobre su desarrollo. Fue nombrado presidente de la Sociedad Internacional el francés Dr. E. Mazeman.

\section{AGRADECIMIENTOS}

Nuestro agradecimiento a los Sres. Ricardo Pellejero y D. Jordi Beneit, bibliotecarios de la Fundación Puigvert de Barcelona, por las facilidades dadas para la revisión de los originales de las Actas de los Congresos.

\section{BIBLIOGRAFÍA y LECTURAS RECOMENDADAS ( ${ }^{*}$ lectura de interés $y^{* *}$ lectura fundamental)}

1. Actas de los Congresos de la Asociación Internacional de Urología de 1908 y 1911.

2. Actas de los Congresos de la Sociedad Internacional de Urología de 1921, 1924, 1927, 1930, 1933, 1947, 1949, 1952, 1955, 1958, 1961, 1964, 1967. 1970, 1973, 1976, 1979, 1982, 1985, 1988, 1991, 1994 y 1997.

3. Archivos Españoles de Urología, Madrid, de 1944 a 1973.

4. Clínica y Laboratorio, VIII Congreso de la Sociedad Internacional de Urología, Zaragoza, 1949.

5. Cirugía, Ginecología y Urología, de 1952 a 1966.

6. La Medicina Íbera, Madrid, de 1924 a 1933.

7. NEGRETE DE LOS REYES, C.: "Algunos apuntes acerca del primer congreso de la Asociación Internacional de Urología”. Rev. Iberoamericana de Ciencias Médicas: 451-457, Madrid, noviembre de 1908.

8. PULIDO MARTÍN, A.: "Memorias de un médico". Edit. Madrid, 1965. 